7 Sonnenblick M, Melzer E, Rosin AJ. Body positional effect on gas exchange in unilateral pleural effusion. Chest 1983;83:784-6.

8 Filshie J, Penn K, Ashley S, Davis CL. Acupuncture for the relief of cancer-related breathlessness. Palliat Med 1996;10:145-50.

9 Bredin M, Corner J, Krishnasamy M, Plant $\mathrm{H}$ et al. Multicentre randomised controlled trial of nursing intervention for breathlessness in patients with lung cancer. BMJ 1999;318:901-4.

10 Hately J, Laurence V, Scott A, Baker R, Thomas P. Breathlessness clinics within specialist palliative care settings can improve the quality of life and functional capacity of patients with lung cancer. Palliat Med 2003;17:410-7.

11 Booth S, Wade R, Johnson M, Kite S et al. The use of oxygen in the palliation of breathlessness. A report of the expert working group of the Scientific Committee of the Association of Palliative Medicine. Review. Respir Med 2004;98:66-77.

12 Pauwels RA, Buist AS, Calverley PM, Jenkins CR, Hurd SS; GOLD Scientific Committee. Global strategy for the diagnosis, management, and prevention of chronic obstructive pulmonary disease. NHLBI/WHO Global Initiative for Chronic Obstructive Lung Disease (GOLD) Workshop summary. Review. Am J Respir Crit Care Med 2001;163:1256-76.

13 Muers MF. Opioids for dyspnoea. Thorax 2002;57:922-3.

14 Jennings AL, Davies AN, Higgins JP, Gibbs JS, Broadley KE. A systematic review of the use of opioids in the management of dyspnoea. Thorax 2002;57:939-44.

15 Allen S, Raut S, Woollard J, Vassallo M. Low dose diamorphine reduces breathlessness without causing a fall in oxygen saturation in elderly patients with end-stage idiopathic pulmonary fibrosis. Palliat Med 2005;19: 128-30.

16 Ahmedzai S, Davis C. Nebulised drugs in palliative care. Thorax 1997;52(Suppl 2): S75-7.

17 Shee CD. Palliation in chronic respiratory disease. Review. Palliat Med 1995;9:3-12.

18 Kohara H, Ueoka H, Aoe K, Maeda T et al Effect of nebulized furosemide in terminally ill cancer patients with dyspnea. J Pain Symptom Manage 2003;26:962-7.

19 Ong KC, Kor AC, Chong WF, Earnest A, Wang YT. Effects of inhaled furosemide on exertional dyspnea in chronic obstructive pulmonary disease. Am J Respir Crit Care Med 2004;169:1028-33.

\section{The principles of cancer pain management}

Marie Fallon MD FRCP(Glas) FRCP(Ed) MRCGP, Reader in Palliative Medicine, University of Edinburgh, Edinburgh Cancer Centre, Western General Hospital, Edinburgh

Sandra McConnell MB ChB MRCP, Specialist Registrar in Palliative Medicine, Western General Hospital, Edinburgh

\section{Clin Med 2006:6:136-9}

Pain occurs in up to $70 \%$ of patients with advanced cancer and in about $65 \%$ of patients dying from non-malignant disease. Pain can be controlled in most (about 80\%) using a simple, stepwise approach and a limited number of analgesics as set out in the World Health Organization (WHO) analgesic ladder (Fig 1). ${ }^{1}$ The severity of the pain dictates the strength of analgesic and the pathophysiology dictates the adjuvant analgesic to be prescribed.

About $10 \%$ of patients will require more complex, sometimes invasive, management to control their pain, leaving another $10 \%$ with cancer pain that is difficult to control.

\section{Assessment of pain}

The keystone to successful management is assessment which should reveal:

- patient characteristics, including mood

- pain characteristics

- drug responsiveness.

\section{Patient characteristics}

Characteristics relating to the patient are:

- previous problems with analgesia

- fear of opioids

- deranged biochemistry, and

- mood.

Assessment of mood in a patient with uncontrolled cancer pain should be made with an open mind. If depressed, patients

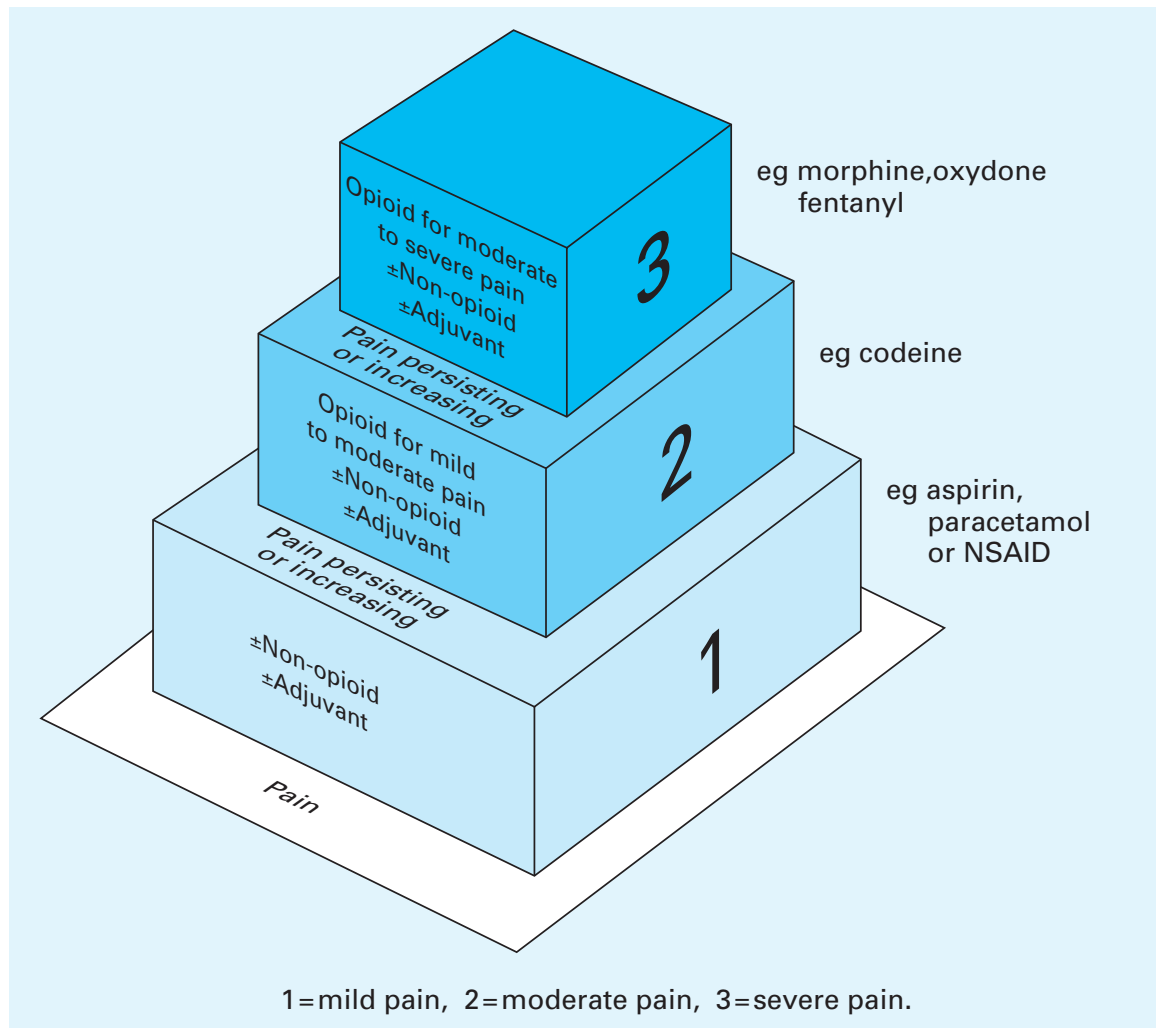

Fig 1. World Health Organization three-step analgesic ladder. NSAID = non-steroidal anti-inflammatory drug. ${ }^{1}$ 
will often state that this results from severe pain affecting many aspects of quality of life. Many patients will have improved mood with adequate pain control but some will require an antidepressant. This is particularly likely in established, severe depression.

\section{Pain characteristics}

Characteristics relating to the patient's pain are:

- cancer-pain related: this may have characteristics of a classical cancer pain syndrome such as liver capsule pain, lumbosacral plexopathy, brachial plexopathy, coeliac plexus infiltration, raised intracranial pressure

- treatment-related: for example, platinum-induced neuropathy, radiotherapy-induced oesophagitis, radiotherapy-induced plexopathies

- non-cancer pain: for example, osteoarthritis.

\section{Drug responsiveness}

Drug responsiveness may relate to previous analgesics tried, current analgesia and, if exposed to an opioid, degree of opioid responsiveness - one of the most important prognostic factors in pain control. ${ }^{2}$

\section{Total pain}

One of the central tenets of modern palliative care was Dame Cicely Saunders' concept of 'total pain', first described in the 1960s. ${ }^{3}$ This concept is now understood in terms of the sophisticated interaction in the nervous system of physical and emotional aspects which make up the subjective feeling of pain. The non-nociceptive factors are integrated with the nociceptive factors and can magnify the subjective pain sensation experienced (Fig 2).

\section{The World Health Organization analgesic ladder (Fig 1)}

The three-step WHO analgesic ladder remains the mainstay of the approach to analgesia. However, non-pharmacological treatments, together with appropriate interventions such as surgery, radiotherapy, bisphosphonates, chemotherapy and other tumoricidal treatments, should be integrated with this analgesic approach, as appropriate. ${ }^{4}$

\section{Adjuvant analgesics (Table 1)}

\section{NSAIDs and steroids}

Non-steroidal anti-inflammatory drugs (NSAIDs) can be helpful in cancer pain, particularly pain associated with bone metastases, soft tissue infiltration and inflammation. Steroids are also effective in relieving pain caused by inflammation and oedema. However, side effects often limit their usefulness, especially in the longer term.

\section{Tricyclic antidepressants and anticonvulsants}

Tricyclic antidepressants are effective in relieving neuropathic pain. There are no significant differences in efficacy between the different tricyclic antidepressants (number needed to treat $(\mathrm{NNT})=3)$. Unfortunately, side effects often limit their use.

There is a lack of high-level evidence of efficacy of selective serotonin reuptake inhibitors for treating neuropathic pain.

The anticonvulsants carbamazepine, phenytoin, sodium valproate, gabapentin and pregabalin are effective in treating neuropathic pain $(\mathrm{NNT}=3)$. Gabapentin and pregabalin are licensed for treatment

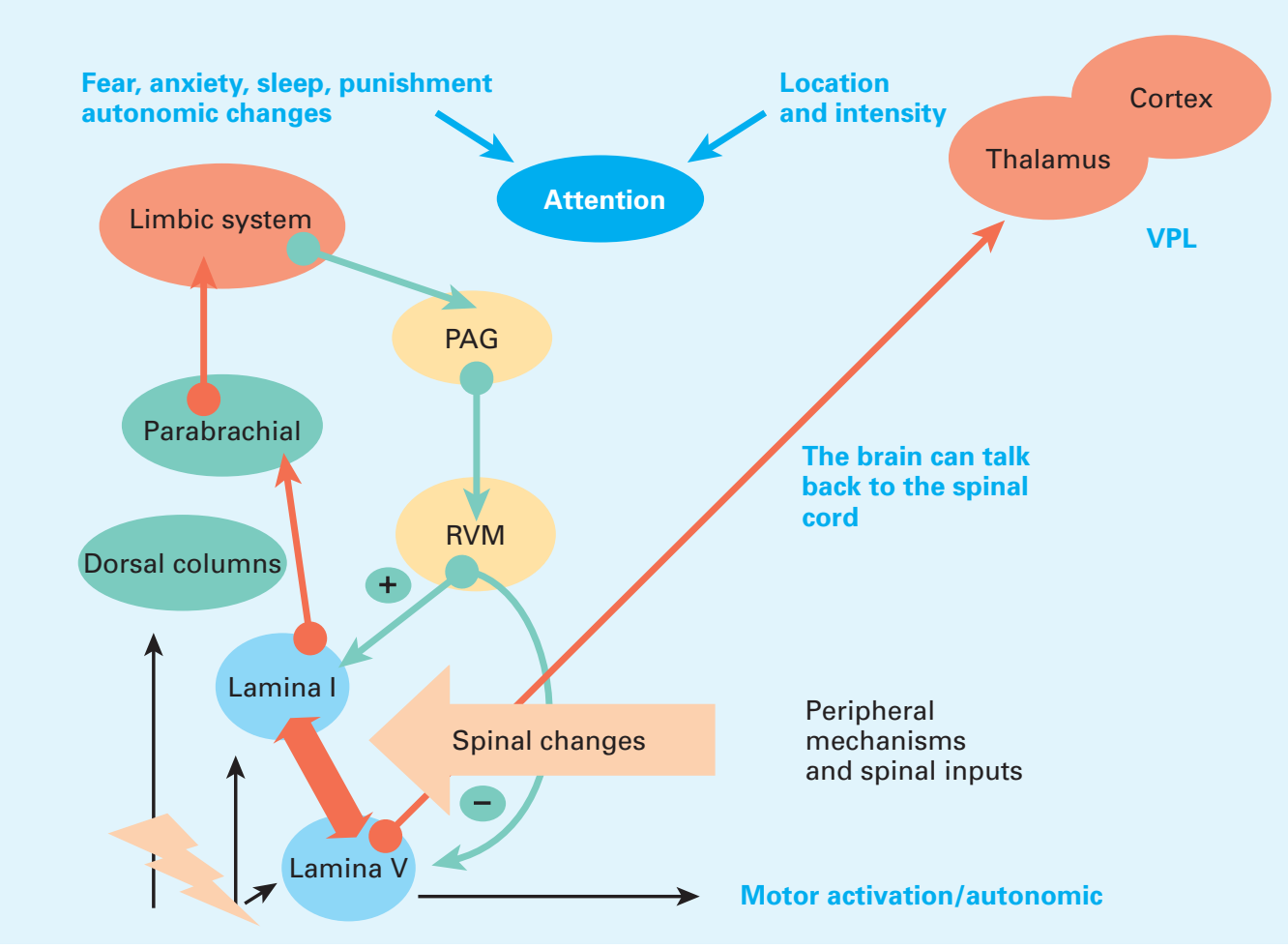

Fig 2. The components contributing to the subjective sensation of pain.

PAG = periaqueductal gray; RVM = rostroventromedial medulla; VPL = thalamic nucleus ventroposterior lateralis. 
of neuropathic pain. Benefit is independent of pain characteristics.

There is no measurable difference in the analgesic benefit of the two drug classes in neuropathic pain or in the NNT before a minor or major adverse event occurs. Gabapentin and pregabalin seem to have a more favourable side effect profile in many patients, but systematic examination of this in relation to other adjuvants is awaited in patients with cancer pain. ${ }^{5}$

Antidepressants and anticonvulsants may occasionally be prescribed simultaneously but it is good clinical practice to introduce only one drug at a time. Bisphosphonates have been shown to delay the onset of symptomatic bone metastases and their use for acute bone pain is currently being investigated.

\section{Opioids}

\section{Opioid analgesics for moderate and severe pain}

Morphine is the most commonly used opioid in this group. When possible, it should be given by mouth, the dose tailored to each patient with doses repeated at regular intervals to prevent the pain from returning. There is no arbitrary upper limit, but negative attitudes to using morphine still exist. The skilled use of morphine will confer benefit rather than harm, but many patients express fears, which should be discussed.

Dose titration. A normal release formulation of morphine (either elixir or tablet), with a rapid onset and short duration of action, is preferred for dose titration. The simplest method is to prescribe a regular, four-hourly dose but to allow extra doses of the same amount for 'breakthrough pain' as often as necessary. The daily requirements may be reassessed after 24-48 hours and the regular dose adjusted as necessary. This process is continued until satisfactory pain relief is achieved.

By this method, the many factors that contribute to the variability in dose are taken into account, including:

- the severity of pain

- the type of pain

- the affective component of pain, and

- variation in pharmacokinetic parameters.

The regular four-hourly dose may range from $5-10 \mathrm{mg}$ to $250 \mathrm{mg}$ or more (or the equivalent in controlled-release (CR) tablets). The dose is titrated against effect, but very few patients need high doses with most requiring less than $200 \mathrm{mg}$ a day.

Maintenance of pain relief. Once pain is relieved, maintenance will be with a CR morphine preparation, available as a once-daily preparation that remains effective for 24 hours or a twice daily preparation with effects that last 12 hours.

\section{Which opioid for cancer pain?}

Comparative trials of opioids in cancer pain are extremely difficult to perform and do not always answer our questions because of the complexity of the populations studied.

There is no strong evidence for the superiority of one opioid over another. However, a number of factors play different roles in the balance between analgesia and side effects including pharmacokinetic profile, route of administration and genetic variability in opioid responses. The transdermal route with TTS-fentanyl (transdermal therapeutic system) or transdermal buprenorphine can be useful in patients with swallowing

Table 1. Adjuvant analgesics.*

\begin{tabular}{|c|c|c|c|}
\hline Drug & Dosage & Indications & Side effects ${ }^{* *}$ \\
\hline NSAIDs eg diclofenac & 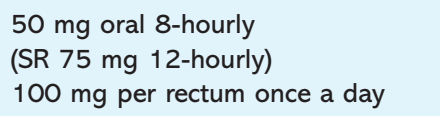 & $\begin{array}{l}\text { Bone metastases, soft tissue } \\
\text { infiltration, liver pain, } \\
\text { inflammatory pain }\end{array}$ & $\begin{array}{l}\text { Gastric irritation and bleeding, } \\
\text { fluid retention, headache } \\
\text { Caution in renal impairment }\end{array}$ \\
\hline Steroids eg dexamethasone & $\begin{array}{l}\text { 8-16 mg per day; use morning; } \\
\text { titrate down to lowest dose which } \\
\text { controls pain }\end{array}$ & $\begin{array}{l}\text { Raised intracranial pressure, nerve } \\
\text { compression, soft tissue infiltration, } \\
\text { liver pain }\end{array}$ & $\begin{array}{l}\text { Gastric irritation if used together } \\
\text { with NSAID, fluid retention, } \\
\text { confusion, Cushingoid } \\
\text { appearance, candidiasis, } \\
\text { hyperglycaemia }\end{array}$ \\
\hline Gabapentin & $\begin{array}{l}\text { 100-300 mg nocte (starting dose) } \\
\text { (titrate to } 600 \text { mg 8-hourly; may } \\
\text { need higher dose) }\end{array}$ & Nerve pain of any aetiology & Mild sedation, tremor, confusion \\
\hline $\begin{array}{l}\text { Amitriptyline } \\
\text { (evidence for all tricyclics) }\end{array}$ & $\begin{array}{l}25 \mathrm{mg} \text { nocte (starting dose) } \\
10 \mathrm{mg} \text { nocte (elderly) }\end{array}$ & Nerve pain of any aetiology & $\begin{array}{l}\text { Sedation, dizziness, confusion, } \\
\text { dry mouth, constipation, urinary } \\
\text { retention } \\
\text { Avoid in cardiac disease }\end{array}$ \\
\hline $\begin{array}{l}\text { Carbamazepine (evidence } \\
\text { for all anticonvulsants) }\end{array}$ & 100-200 mg nocte (starting dose) & Nerve pain of any aetiology & $\begin{array}{l}\text { Vertigo, sedation, constipation, } \\
\text { rash }\end{array}$ \\
\hline Bisphosphonates & Various regimens & Malignant bone pain & $\begin{array}{l}\text { Hypocalcaemia, 'flu-like } \\
\text { symptoms }\end{array}$ \\
\hline
\end{tabular}

\footnotetext{
* Drugs with a primary indication other than pain, but analgesic when used as above.

** In the elderly all drugs can cause confusion.

NSAID = non-steroidal anti-inflammatory drug; $\mathrm{SR}=$ slow release.
} 
difficulties as the drug is released into the skin at a constant rate depending on the dose of patch chosen. ${ }^{6}$ Oxycodone or hydromorphone may provide an alternative to morphine if hallucinations or disturbed sleep are troublesome.

Any opioid can accumulate in renal dysfunction. The various metabolites from the different opioids are not fully understood and care should always be taken in this situation. Opioid doses are usually smaller, with increased dosing intervals or even administered on an 'as required' basis. It is usually acceptable to consider drugs such as fentanyl, alfentanyl, hydromorphone and buprenorphine in renal dysfunction. ${ }^{7}$

\section{Tolerance, addiction and physical dependence}

Tolerance to opioids is rarely seen in the clinical practice of managing cancer pain. Requirements for increasing doses of morphine can usually be explained by progressive disease rather than by pharmacological tolerance. Psychological dependence or addiction is not a problem except in patients with pre-existing addiction. If alternative methods of pain control are used (such as nerve blocks), it is usually possible to reduce the dose of the analgesic or even withdraw it without adverse psychological effects. Physical dependence can occur; this physiological response can manifest itself as a flu-like illness in some patients if an opioid is discontinued suddenly.

\section{Opioid toxicity}

There is wide variation over time in the dose of opioid which can be tolerated, both between and within individuals. The ability to tolerate a particular dose depends on the degree of responsiveness of the pain to opioid analgesia, prior exposure to opioids, rate of titration of the dose, concomitant medication and renal function. Toxicity can be a frightening and life-threatening experience but it is usually reversible if diagnosed early.

Opioid toxicity may present as subtle agitation, seeing shadows at the periphery of the visual field, vivid dreams, visual and auditory hallucina-

\section{Key Points}

Pain affects $70 \%$ of patients with advanced cancer

Successful management depends on full assessment of patient and pain characteristics and drug responsiveness

Most patients' pain can be controlled by applying the three-step WHO analgesic ladder

Non-pharmacological treatments together with appropriate interventions should be integrated with drug treatment as necessary

Opiod dose should be titrated using short-acting normal release opiod

Opiod toxicity should be monitored actively and treated promptly

KEY WORDS: adjuvants, cancer pain, opioids, total pain, toxicity, World Health Organization

tions, confusion and myoclonic jerks. Agitated confusion may be interpreted as uncontrolled pain and further opioids given. A vicious cycle then follows in which the patient is given sedation and may become dehydrated, resulting in the accumulation of opioid metabolites and further toxicity.

Management of opioid toxicity includes reducing the dose of opioid, ensuring adequate hydration and treating the agitation with haloperidol (1.5-3 mg orally or subcutaneously, repeated hourly as needed). If toxicity is severe and opioid analgesia is still needed, a switch in opioid usually leads to a faster recovery.

\section{References}

1 Zech DF, Grond S, Lynch J, Hertel D, Lehmann KA. Validation of World Health Organization Guidelines for cancer pain relief: a 10-year prospective study. Pain 1995;63:65-76.

2 Fallon M, Hanks GW. Opioid responsiveness - sense or nonsense? The Pain Clinic 1993; 6:205-6.

3 Saunders C. Into the valley of the shadow of Death. A personal therapeutic journey. BMJ 1996;313:1599-1601.

4 World Health Organisation. Cancer pain relief and palliative care, 2 nd edn. Geneva: WHO, 1996.

5 Fallon M, Walley JD. Neuropathic pain: evidence-base and clinical effectiveness of novel interventions. In: Hoy A, Finlay I, Miles A (eds). The effective prevention and control of symptoms in cancer. UK Key Advances in Clinical Practice Series. London: Aesculapius Medical Press, 2004.
6 Fallon MT. Opioid rotation: does it have a role? Palliat Med 1997;11:177-8.

7 Fallon MT, Hanks GW, Cherny N. Cancer pain management. BMJ 2006 (in press). 